\title{
Container-breeding mosquitoes and predator community dynamics along an urban-forest gradient: the effects of habitat type and isolation
}

Robbie Weterings ${ }^{\mathrm{a}, \mathrm{b}, *}$, Chanin Umponstira ${ }^{\mathrm{b}}$, Hannah L. Buckley ${ }^{\mathrm{c}}$

${ }^{a}$ Cat Drop Foundation, Boorn 45, 9204 AZ, Drachten, The Netherlands.

${ }^{\mathrm{b}}$ Faculty of Agriculture Natural Resources and Environment, Naresuan University, 99 Moo 9

Phitsanulok-Nakhonsawan Road Tambon Tapho, Muang Phitsanulok, 65000 Thailand

${ }^{c}$ Department of Ecology, Lincoln University, PO Box 85048, Lincoln 7647, Canterbury, New Zealand

${ }^{*}$ Corresponding author at: Tel.: +31512540714

E-mail address: r.weterings@catdropfoundation.org 


\begin{abstract}
Environmental disturbances such as deforestation, urbanization or pollution have been widely acknowledged to play a key role in the emergence of many infectious diseases, including mosquitoborne viruses. However, we have little understanding of how habitat isolation affects the communities containing disease vectors. Here, we test the effects of habitat type and isolation on the colonization rates, species richness and abundances of mosquitoes and their aquatic predators in water-filled containers in northwestern Thailand. For eight weeks water-filled containers were monitored in areas containing forest, urban and agricultural habitats and mixtures of these three. Mosquito larvae of the genera Aedes and Culex appeared to be differentially affected by the presence of the dominant predator; Toxorhynchites splendens (Culicidae). Therefore, a predation experiment was conducted to determine predator response to prey density and its relative effects on different mosquito prey populations. Colonization rates, species richness and abundances of mosquito predators were strongly related to forest habitat and to the distance from other aquatic habitats. Areas with more tree cover had higher predator species richness and abundance in containers. Containers that were close to surface water were more rapidly colonized than those further away. In all habitat types, including urban areas, when predators were present, the number of mosquito larvae was much lower. Containers in urban areas closer to water-bodies, or with more canopy cover, had higher predator colonization rates and species richness. Toxorhynchites splendens (Culicidae) preyed on the larvae of two mosquito genera at different rates, which appeared to be related to prey behaviour. This study shows that anthropogenic landscape modification has an important effect on the natural biological control of mosquitoes. Vector control programs and urban planning should attempt to integrate ecological theory when developing strategies to reduce mosquito populations. This would result in management strategies that are beneficial for both public health and biodiversity.
\end{abstract}


Keywords: Culicidae, Isolation, Predator-prey community, Toxorhynchites splendens, vector ecology. 


\section{Introduction}

Environmental disturbances such as deforestation, urbanization or pollution have been widely acknowledged to play a key role in the emergence of many infectious diseases (Guerra, Snow, \& Hay 2006; Yasuoka \& Levins 2007; Patz, Olson, Uejio, \& Gibbs 2008) through severe alterations to local hydrology, temperature and light regimes (Meher-Homji 1991; Culf, Esteves, Marques Filho, \& da Rocha 1996). Water availability, temperature and light are strong drivers of the development of mosquitoes and the regulation of their population densities (Clements 1999). Thus, the effects of such environmental changes are particularly evident in mosquito-borne diseases. For example, the main mosquito vector of dengue fever, Aedes aegypti L. 1762, has been associated with urbanization and deforestation (Vanwambeke, Lambin, Eichhorn, Harbach, Oskam, et al. 2007; Cox, Grillet, Ramos, Amador, \& Barrera 2007) and malaria and its vectors have also been positively related to deforestation in South America and Africa (Overgaard, Ekbom, Suwonkerd, \& Takagi 2003; Yasuoka \& Levins 2007).

Deforestation and urbanization not only affect mosquito populations, but also those of their predators (Samways \& Steytler 1996; Lundkvist, Landin, \& Karlsson 2002; Carlson, Keating, Mbogo, Kahindi, \& Beier 2004; Cox et al. 2007; Fischer \& Schweigmann 2008). For example, Carlson et al. (2004) showed that these predators are less likely to colonize water bodies in urban environments. Several studies have also shown that habitat isolation strongly affects the composition of freshwater invertebrate communities (Shulman \& Chase 2007; Chase \& Shulman 2009). An increase in mosquito predators can have a strong effect on the population density of mosquitoes, and many aquatic predator species are known to strongly suppress the abundance of mosquitoes (Fincke, Yanoviak, \& Hanschu 1997; Blaustein, Blaustein, \& Chase 2005; Culler \& Lamp 2009). Further, in the interests of disease vector control, it is important to understand how mosquito-predator communities may be affected by 
anthropogenically-altered landscapes.

Here, we present a study that compares mosquito predator colonization and mosquito larval abundance along a gradient of urbanized and forest habitats. We investigated the effects of habitat type and isolation on the colonization rate of mosquitoes and predators in water-filled containers. We were particularly interested in Aedes mosquitoes, a genus of mainly container and tree-hole breeding mosquitoes which also contains all vector species of dengue fever (Clements 2012), and its predators. Theory predicts that (1) species richness increases when habitat patches within a matrix of unsuitable habitat increase in size and (2) colonization rates are higher when a habitat patch is nearer to a source habitat (MacArthur \& Wilson 1967). For example, Caillouët et al. (2008) investigated the colonization of mosquito larvae and their predators in flooded (swimming) pools. They found that predator species richness (fish) was negatively related to the distance from the source habitat. Shulman and Chase (2007) observed a similar pattern for invertebrates in an experiment with plastic tubs at different distances from three different source ponds. Mosquito predator richness was negatively related to the distance to the source ponds.

The effects of habitat fragmentation and isolation on predator-prey interactions are complex because they involve two or more interacting species and these factors may affect each species differently (Lei \& Hanski 1997; Mazerolle, Villard, De, \& Moncton 1999; Orrock, Danielson, Burns, \& Levey 2003). For instance, experimental and modeling studies have shown that the surrounding matrix may provide suitable habitat for the prey, which can therefore disperse easily, while the same habitat may be strongly avoided by the predator (Nachman 1987; Lei \& Hanski 1997). Such differences result in situations in which the communities are not at equilibrium and local extinctions of predator and/or prey are a consequence (Lei \& Hanski 1997; Hauzy, Gauduchon, Hulot, \& Loreau 2010). Prey populations may flourish due to a lack of predation or predators may over-exploit their prey when 
dispersal rates are too high (Walde \& Nachman 2004; Morin 2011). In fragmented landscapes, dispersal is an important factor in the persistence of predator-prey metacommunities (Crowley 1981; Holyoak \& Lawler 1996; Hauzy et al. 2010). A solid understanding of the effects of habitat fragmentation on predator-prey interactions is thus critical for the conservation of species and the management of biological control programs; however, little research has explicitly addressed community-level effects of landscape factors on disease vector systems (Carlson, Keating, Mbogo, Kahindi, \& Beier 2004; Chase \& Shulman 2009).

We used water-filled containers in rural Thailand to investigate the colonization of mosquito predators in different habitat types. We expected that expected that these predators more rapidly colonize containers in forest habitats due to the presence of more suitable habitat and lower habitat isolation, than those in urban or agricultural habitats. We predicted that the amount of surface water in the surrounding area would have a positive effect on the colonization rate of predators. Mosquito larval abundance in containers in these habitats could therefore possibly be lower due to increased predation. Containers in areas in which forest habitats, as well as water-bodies, that were less isolated were also predicted to be more rapidly colonized by predators. Thus, we expected that containers in areas with many forest habitat patches and that were closer to surface water would be colonized by predators earlier. Further, we specifically measured the effect of predator presence in the containers on the density of mosquito larvae, with a particular focus on Aedes spp., in an attempt to link habitat effects to mosquito densities. We predicted that containers with predators would have lower mosquito larval densities compared to containers without predators. During the study it became evident that a single predator, Toxorhynchitis splendens (Wiedemann), affected mosquito larval densities most. In order to quantify its role in the regulation of prey population densities, we conducted an experiment to assess prey consumption. 


\section{Materials and methods}

\section{Study area}

We selected 22 sampling sites in the Kamphaeng Phet province in northwestern Thailand (Fig. 1) where each was a circular area with a $250 \mathrm{~m}$ radius centered at a large tree or group of smaller trees. In non-forest habitats these were either large solitary trees or very small patches of vegetation that did not exceed 10 by $10 \mathrm{~m}$. The $250 \mathrm{~m}$ radius was based on the mean maximum distance that Aedes mosquitoes flew in a study in Thailand (266 m) (Harrington et al. 2005). The sites encompassed forest habitats, agricultural habitats, urban habitats, surface water and mixtures of these four. Within each site the following habitat types were mapped by hand: forest (secondary forest, riparian forest, plantation and parks), water (lakes, rivers, ponds and pools), agriculture (cassava, sugar cane, bare land and grass) and urban (buildings and roads). Forest habitats included all areas with a canopy cover of at least 35\%, following Anderson (1986). Areas with less tree cover were grassy areas with solitary trees, and were classified as agriculture these included pastures, parks and gardens.

\section{Water-filled container experiment}

We conducted a field experiment using 5-L black plastic containers, to investigate the effects of habitat variation and isolation on the colonization rate of mosquito predators and its subsequent effect on mosquito larval densities. The container size was arbitrarily chosen as the minimum size to avoid complete drying up of the containers. One container was placed in each site at the start of the rainy season on the $3^{\text {rd }}$ of June, 2013. The rainy season was selected because it is the period of peak mosquito abundances and ensured our containers would not dry up. Containers were placed 1.5 to $2 \mathrm{~m}$ up a tree located at the approximate centre of each site. We covered the container bottoms with $2 \mathrm{~cm}$ of dead 
leaves to provide nutrients and refuge for colonizing organisms and added $1.5 \mathrm{~L}$ rainwater. The type of leaves varied because in each case these were collected under the same tree in which the container was placed. A 15 to $20 \mathrm{~cm}$ long stick was added to function as an oviposition substrate. The containers were checked weekly for the presence of fauna for a period of two months, resulting in up to eight sampling occasions for each container. Containers were emptied in a large, white tray in which we identified and counted the number of predators. Mosquito larvae were classified into six abundance categories: 1-10, 10-50, 50-100, 100-200, 200-500 and more than 500 larvae. These estimates were made for all mosquito larvae and then separately for each genus of mosquitoes. We did not count the exact number of mosquito larvae because this would have increased the chance of accidentally damaging and/or killing larvae and, therefore, would potentially influence the numbers in subsequent counts. The number of individuals of the large mosquitoes in the genus Toxorhynchites were counted exactly because these are important predators of vector mosquitoes (Clements 1999). After we counted both predators and mosquito larvae, the water, leaves and organisms were returned and the container was placed back into the tree.

Three response variables were used to estimate the effects of habitat variation and isolation on aquatic community structure and dynamics. First, the first week in which a tree-hole was colonized by a predator (the speed of colonization) was re-classed so that the first week received the highest number (eight) and the last week the lowest number (one). Containers that remained uncolonised throughout the study were given the value zero. Second, the total number of weeks that a tree-hole contained a predator was calculated as a percentage in which we used the total number of weeks a container was colonized relative to the duration of the experiment for that specific container. Third, the cumulative number of predator species was counted during the entire period per container. Although the number of predators was low and dominated by one species, we decided to include species richness because of the 
large differences in life history among the species. The number of weeks was not equal for all containers because several were stolen or vandalised, but this was accounted for by using a weighted analysis. Vandalism reduced our number of sample sites from 28 to 22; of these 22 sites, only 11 were sampled for the entire duration of the study. Of the remaining 11 sites, only four sites were sampled fewer than five times.

Variables representing habitat type and isolation were calculated using ArcGIS 10.1 (ESRI 2012) and Fragstats 4.1 (McGarigal \& Marks 1994). The mapped habitat types were used to calculate the total area of each habitat type in the sampling sites. The closest distances from each tree-hole to a forest habitat patch and to surface water were measured on digital maps. We used the Fragstats software to calculate connectance of forest and surface water habitats. Connectance is a landscape index based on a threshold dispersal distance for which habitat patches are still considered to be connected; it is the percentage of the maximum number of connected habitat patches (McGarigal \& Marks 1994). We used a threshold distance of $25 \mathrm{~m}$, which we based on a catch and release study where the mean ( \pm SE) flying distances of Aedes aegypti were $36 \pm 7 \mathrm{~m}$ for outdoor released mosquitoes and $40 \pm 22 \mathrm{~m}$ for indoor released mosquitoes (Harrington et al. 2005). Due to the large standard errors we reduced this distance for our study to ensure that habitats were indeed connected.

The data for the first week of colonization were analysed with weighted hurdle models (Zeileis, Kleiber, \& Jackman 2008) because the data had a slight inflation in zeros, which caused overdispersion in generalized linear models. We used a hurdle model instead of a zero-inflated Poisson model because of the experimental nature of the data meaning that zero counts were actual zeros, not missing counts (Zuur, Ieno, Walker, Saveliev, \& Smith 2009). The hurdle model consisted of two parts, one part that modelled the zeros in the data and one part that modelled the counts (Zuur, Ieno, Walker, Saveliev, \& Smith 2009). The zero hurdle model assumed a binomial distribution, used a logit link function and 
modelled the presence-absence of predators. The count hurdle model modelled the speed of colonization where predators were present. This count model assumed a Poisson distribution and used a $\log$ link function. We used model weights based on the number of weeks each bucket was monitored. Analyses were conducted with RStudio 0.97.551 (Rstudio, Boston) built on R 3.0.1 (R Development Core Team, Vienna) using the 'pscl' package (Jackman, Tahk, Zeileis, Maimone, \& Fearon 2013). Our models were based on a priori hypotheses developed following the multi-model inference approach described by Anderson (2008). All explanatory variables were standardized to a mean of zero and standard deviation of one (Zuur, Ieno, Walker, Saveliev, \& Smith 2009). The variables representing the area of the different habitat types were highly collinear, therefore, we performed a principle component analysis to calculate uncorrelated variables representing habitat variation (Härdle \& Simar 2003). Models were validated by assessing plots of Pearson residuals versus the fitted values and all explanatory variables (Zuur, Ieno, Walker, Saveliev, \& Smith 2009). Models were compared using the AICc score (Anderson 2008). Finally, we used model weights to calculate an averaged model, based on all a priori hypothesized models (Anderson 2008). Additionally we calculated Spearman's correlation coefficient to quantify the relationship between the first week of colonization, predator species richness and relative duration of predator colonization versus the different habitat types.

Cumulative Link Mixed Models (CLMM) implemented with the 'ordinal' R package (Christensen 2012) were used to test the specific effect of predators on the density of all mosquito larvae and on Aedes spp. larvae (Christensen 2012). We used the mosquito density categories as the response variable and the presence-absence of predators as the explanatory variable. Every sampling occasion was treated as an input record with up to eight records per container. To account for the repeated measures nature of these data, we included 'site' and 'week' as random effect terms.

Additionally, we sampled 20, pre-established water-filled containers of varying sizes ( 2 to $50 \mathrm{~L}$ ) 
in different habitat types in order to get an overview of the predator species that are present in the study area. We sampled these containers by sweeping a hand-held net through the container for 30 seconds. The content of the net was then emptied in a white plastic container, where all predators were identified.

\section{Predation experiment}

Preliminary analyses during field work revealed two interesting patterns: (1) There was one dominant predator species (Toxorhynchites splendens) and (2) the numbers of mosquito larvae in different genera were differentially reduced. Therefore, upon completion of the tree-hole experiment we collected all $T$. splendens individuals and conducted a small experiment to test for differences in predation on Culex and Aedes larvae. For this experiment we used ten, 1.5-L transparent plastic containers filled with $1 \mathrm{~L}$

of rainwater. We added one T. splendens specimen to each container. Then we added equal amounts of 3rd and 4th instar Aedes spp. and Culex spp. larvae at different densities per container. Different prey densities were used in order to assess a prey density effect on the number of consumed prey. We used two containers with 10 mosquito larvae (five Aedes spec. and five Culex spec.), three with 20 larvae (10 Aedes spec. and 10 Culex spec.), three with 30 larvae (15 Aedes spec. and 15 Culex spec.) and two with 40 larvae (20 Aedes spec. and 20 Culex spec.). After 24 hours we counted the number of living larvae in each genus.

To test for differences in prey consumption with regard to different prey species we used a generalized linear mixed effects model (GLMM) with Poisson distributed errors and a log link function. The number of mosquitoes eaten per genus was the response variable. Prey genus and prey density were added as explanatory variables and the identity of each container was added as a random effect to account for the multiple observations per container. We log transformed prey density to account for 
non-linearity of these data. The R package 'Ime4' was used for the GLMM analysis (Bates, Maechler, Bolker, \& Walker 2013). 


\section{Results}

The mosquito (Culicidae) larvae belonged to four genera: Aedes, Culex, Toxorhynchites and Armigeres. Several containers were also occupied by Chironomidae (Diptera) larvae, Psychodidae (Diptera) larvae, Machilidae (Archaeognatha) and Asellota (Isopoda). Out of all 22 containers, 14 were colonized by four different species of predators during the experimental period (Table 1). The samples from the preestablished containers contained eight different mosquito predator species/genera (Table 1).

Hurdle models revealed that habitat and the distance to forest habitat strongly affected predator presence (Tables 2 and 3). Connectance of surface water was less important. Predator presence was positively related to habitat and had a negative relationship with distance to forest habitat; containers in sites further from forest were less likely to be colonized by a predator. When considering colonization speed in areas where predators were present, connectance of surface water was the most important explanatory variable, followed by habitat (Table 3). In this case, the role of distance to forest habitat was negligible. Connectance of surface water positively affected colonization speed. In the averaged model the connectance of forest habitat was also included, which played a minor role in the presenceabsence model, and a negligible role in the count model.

The correlation coefficients show in more detail the effects of the different habitat types on the colonization speed (Table 4). The first week that a tree-hole was colonized was strongly associated with forest habitats. Urban and agricultural habitats were less likely to be colonized quickly. The correlation coefficients for the total number of weeks a tree-hole was colonized showed similar results. The number of weeks was strongly, positively associated with forest habitats, while the number of weeks was low in agricultural and urban habitats. The predator species richness per container showed a similar pattern.

The CLMMs showed that the presence of predators significantly reduced the number of 
mosquito larvae (Table 5 and Fig. 2) and that Aedes spp. were relatively more reduced than Culex spp. larvae. This difference was also reflected in the predation experiment. The GLMMs showed that Toxorhynchites splendens fed on significantly more Aedes spp. than Culex spp. larvae (Table 6). The number of prey consumed increased with increasing prey densities in a log-linear fashion. 


\section{Discussion}

Our results show that habitat connectivity drives both population densities and community composition in aquatic invertebrate communities. In accordance with our predictions, aquatic mosquito predator colonization rates and species richness were higher in areas with more forest and/or surface water than in agricultural and urban areas. This is a strong indication that both forest habitat functions as source habitat for container breeding mosquito predator communities. Source habitat is important for the colonization of predator species into new habitats (Levins 1969; Namba, Umemoto, \& Minami 1999;

Frouz \& Kindlmann 2001) and this is especially true for ephemeral habitats like water-filled containers or other rain-filled mosquito breeding habitats (Caudill 2003; Paradise et al. 2008). A lack of predator source habitat can lead to increased prey densities, when prey metapopulations are not dependent on the same source habitat or habitat quality as their predator (Ryall \& Fahrig 2006; Shulman \& Chase 2007; Chase \& Shulman 2009).

It could be argued that areas with more containers or other water-filled objects would have more mosquitoes and more predators. An increased number of containers could represent an increase in the amount of source habitat. However, the proportion of urban habitat was not positively related to variables that represented predator colonization rates even though these habitats are likely to have more containers and other water-filled objects (Kittayapong \& Strickman 1993). In particular, because the forest habitats in this study rarely consisted of large old trees, the number of treeholes in these habitats was likely to be very low (Fan, Shifley, Spetich, Thompson, \& Larsen 2003; Blakely et al. 2008). In addition, only the larval stage of mosquitoes are present in water-filled objects, while the mobile adults are dispersing through the habitat. It is thus safe to assume that the differences in predator colonization observed in this study were caused by the differences in habitat types and habitat isolation.

The distance to forest habitat and the connectivity of surface water explained significant 
variation in predator colonization rates, showing that dispersal rates and connectivity of source habitats are vital in the dynamics and composition of these aquatic communities. When dispersal rates are low, prey abundance is generally high, while predator abundance is low (Eigler 1977; Nachman 1987). This is clearly reflected in the high numbers of mosquito larvae and low numbers of predators in urban and agricultural habitats. Intermediate dispersal rates reduce the chance of local extinctions in the form of rescue effects; these cause relatively higher predator abundance and lower prey abundance (Holyoak et al. 1996; Namba et al. 1999; Hauzy et al. 2010), which were exhibited in this study in those areas where the habitats were better connected. Thus, overall, our results show that the dynamics of these mosquitoes and their aquatic predators can be predicted by landscape conditions.

From a vector control point of view, the time required for a predator to colonize a mosquito breeding habitat is important. These habitats are often ephemeral and are therefore not occupied the whole year round (Lounibos 1983; Bradshaw \& Holzapfel 1988). Toxorhynchites splendens was the most successful predator with regard to rapid colonization of our experimental units, while the majority of predator species observed in the pre-established containers did not manage to colonize the experimental containers within the two months duration of the study. The rate at which predators colonize these ephemeral habitats can strongly influence the population dynamics of mosquitoes in the landscape (Shulman \& Chase 2007; Silberbush \& Blaustein 2011). Orrock et al. (2003) showed that isolation affects species at different trophic levels differently, which is consistent with our results. The negative effects of isolation appear to be particularly large for trophic specialist predators (Lei \& Hanski 1997; Orrock et al. 2003), such as the dominant mosquito predator in our system. Water-filled containers located in the urban environment at relatively large distances from surface water (150 to 500 m) were either colonized by Toxorhynchites splendens only or by no predator. Those urban containers that were colonized by $T$. splendens were often in close proximity of tree cover (30\% or higher canopy 
density), which is reflected in the strong effect of the distance to forest habitat in our models. Nevertheless, these containers were often colonized much later than those in forest habitats. The importance of a single specialist predator in this system within the urban environment makes these urbanized habitats highly prone to increased mosquito abundances.

As predicted, mosquito larval abundances were significantly lower in the presence of predators. Toxorhynchites splendens was likely to be the most important cause of this reduction. In the predation experiment $T$. splendens fed on a large number of mosquito larvae per day (19.2 \pm 1.1 for treatments with 30 and 40 mosquito larvae). This number would likely have been higher had prey densities been increased even further because our predation did not appear to reach a satiation level. Individuals of Toxorhynchites spp. have previously been reported to consume an impressive number of approximately 5,000 1st instar and 300 4th instar mosquito larvae during their complete larval stage (Collins \& Blackwell 2000). Our predation experiment with T. splendens showed that Aedes species were consumed in higher rates than Culex species. Previous studies have suggested that Toxorhynchites is size-selective (Campos \& Lounibos 2000). Our Aedes larvae were indeed larger than the Culex larvae. Nevertheless, when we conducted the experiment it was evident that Aedes larvae showed more movement than Culex larvae (Robbie Weterings, pers. obs.). Sih (1986) compared anti-predator behaviour between $C$. pipiens and A. aegypti in the presence of the predatory water bug Notonecta undulata. Culex pipiens responded strongly to the presence of the predator by reducing movement. This response was less evident for $A$. aegypti and resulted in lower mortality rates for $C$. pipiens. The antipredatory response to Toxorhynchites rutilus by other Aedes species has also been documented to be very small (Juliano \& Reminger 1992). We suggest that the number of consumed Aedes in our experiment were much higher than those of Culex due to this difference in behaviour rather than size. This is supported by the fact that Toxorhynchites spp. hardly ever catch non-moving prey (Clements 
1999).

\section{Conclusion and management implications}

Toxorhynchites has great potential as a biological control agent of disease vector mosquitoes, and has been used as such in many cases (Steffan 1975; Collins et al. 2000). Some of these trials have been successful; however, many have been less productive (Steffan 1975; Collins et al. 2000). The problem with the introduction of Toxorhynchites species has largely been caused by a poor understanding of the ecology and behaviour of these species (Collins et al. 2000). Our results show that T. splendens needs sufficient canopy cover to be able to establish itself within an urban environment. Lack of vegetation within these environments can thus reduce the effectiveness of such programs. Promoting vegetation and parks within urbanized areas can also naturally increase the population of these predators, without the need of introducing these species. Future studies should investigate the effects of "stepping stones" like parks and ponds or "green belts" on mosquito predators in the urban environment. Such measures have the potential to increase biodiversity, species richness and deter pests (Ignatieva, Stewart, \& Meurk 2011). Not only might this cause a reduction in mosquitoes but also increase the intrinsic values and other ecosystem services of the urban environment.

We show that habitat type and isolation have a tremendous effect on the colonization of mosquito predators in container habitats. This study provides evidence that landscapes dominated by urban and agricultural habitats are slowly colonized by mosquito predators due to a lack of source habitat and reduced dispersal. This reduction in predators causes a relative increase in mosquito larval populations. Thus, anthropogenic landscape alteration has considerable effects on the natural biological control of mosquitoes. Existing ecological theories regarding population and community dynamics should be more strongly integrated in the development of biological vector control or predator 
conservation strategies.

\section{Acknowledgments}

The authors would like to thank Mr. Prapai Kaennark, head of the Kamphaeng Phet Silvicultural Research Station, for granting permission to conduct research on their premises and Mr. Tanaphon Kaennark for helping with some of the field work. We also would like to thank the Faculty of Agriculture, Natural Resources and Environment (Naresuan University) and the Cat Drop Foundation for financial support. 


\section{References}

Anderson, E. W. (1986). A guide for estimating cover. Rangelands, 8, 236-238.

Anderson, D. R. (2008). Model based inference in the life sciences: a primer on evidence. New York: Springer.

Bates, D., Maechler, M., Bolker, B., \& Walker, S. (2013). Linear mixed-effect models using Eigen and S4.

Blakely, T. J., Jellyman, P. G., Holdaway, R. J., Young, L., Burrows, B., et al. (2008). the abundance, distribution and structural characteristics of tree-holes in Nothofagus forest, New Zealand. Austral Ecology, 33, 963-974.

Blaustein, L., Blaustein, J., \& Chase, J. (2005). Chemical detection of the predator Notonecta irrorata by ovipositing Culex mosquitoes. Journal of Vector Ecology, 30, 299-301.

Bradshaw, W. E., \& Holzapfel, C. M. (1988). Drought and the organization of tree-hole mosquito communities. Oecologia, 74, 507-514.

Caillouët, K. A., Carlson, J. C., Wesson, D., \& Jordan, F. (2008). Colonization of abandoned swimming pools by larval mosquitoes and their predators following Hurricane Katrina. Journal of Vector Ecology, 33, 166-172.

Campos, A. R. E., \& Lounibos, L. P. (2000). Life Tables of Toxorhynchites rutilus (Diptera: Culicidae) in Nature in Southern Florida. Journal of Medical Entomology, 37, 385-392.

Carlson, J., Keating, J., Mbogo, C. M., Kahindi, S., \& Beier, J. C. (2004). Ecological limitations on aquatic mosquito predator colonization in the urban environment. Journal of Vector Ecology, 29, 
$331-339$.

Caudill, C. C. (2003). Emperical evidence for nonselective recruitment and a source-sink dynamic in a mayfly metapopulation. Ecology, 84, 2119-2132.

Chase, J. M., \& Shulman, R. S. (2009). Wetland isolation facilitates larval mosquito density through the reduction of predators. Ecological Entomology, 34, 741-747.

Christensen, R. H. B. (2012). A Tutorial on fitting Cumulative Link Mixed Models with clmm2 from the ordinal Package.

Clements, A. N. (1999) The Biology of Mosquitoes Volume 2: Sensory Reception and Behaviour. 1st ed. CABI publishing, Wallingford, UK.

Clements, A. N. (2012). The Biology of Mosquitoes: Volume 3, Transmission of Viruses and Interactions with Bacteria. CABI publishing, Wallingford, UK.

Collins, L. E., \& Blackwell, A. (2000). The biology of Toxorhynchites mosquitoes and their potential as biocontrol agents. Biocontrol News and Information, 21, 105-116.

Cox, J., Grillet, M. E., Ramos, O. M., Amador, M., \& Barrera, R. (2007). Habitat segregation of dengue vectors along an urban environmental gradient. The American Journal of Tropical Medicine and Hygiene, 76, 820-826.

Crowley, P. H. (1981). Dispersal and the stability of predator-prey interactions. The American Naturalist, 118, 673-701.

Culf, A. D., Esteves, J. L., Marques Filho, A. de O., \& da Rocha, H. R. (1996). Radiation, temperature and humidity over forest and pasture in Amazonia. In J. H. . Gash, C. A. Nobre, J. M. Roberts, \& R. L. Victoria (Eds.), Amazonian Deforestation and Climate (pp. 175-191). UK: Wiley. 
Culler, L. E., \& Lamp, W. O. (2009). Selective predation by larval Agabus (Coleoptera: Dytiscidae) on mosquitoes: support for conservation-based mosquito suppression in constructed wetlands. Freshwater Biology, 54, 2003-2014.

Eigler, B. P. (1977). Persistence and patchiness of predator-prey systems induced by discrete event population exchange mechanisms. Journal of Theoretical Biology, 67, 687-713.

Fan, Z., Shifley, S. R., Spetich, M. A., Thompson, F. R., \& Larsen, D. R. (2003). Distribution of cavity trees in midwestern old-growth and secondary growth forests. Canadian Journal of Forest Research, 33, 1481-1494.

Fincke, O. M., Yanoviak, S. P., \& Hanschu, R. D. (1997). Predation by odonates depresses mosquito abundance in water-filled tree holes in Panama. Oecologia, 112, 244-253.

Fischer, S., \& Schweigmann, N. (2008). Association of immature mosquitoes and predatory insects in urban rain pools. Journal of Vector Ecology, 33, 46-55.

Frouz, J., \& Kindlmann, P. (2001). The role of sink to source re-colonisation in the population dynamics of insects living in unstable habitats : an example of terrestrial chironomids. 1, 50-58.

Guerra, C. ., Snow, R. ., \& Hay, S. I. (2006). A global assessment of closed forests, deforestation and malaria risk. Annals of Tropical Medicine and Parasitology, 100, 189-204.

Härdle, W. K., \& Simar, L. (2003). Applied Multivariate Statistical Analysis. Heidelberg: Springer.

Harrington, L. C., Scott, T. W., Lerdthusnee, K., Coleman, R. C., Costero, A., et al. (2005). Dispersal of the dengue vector Aedes aegypti within and between rural communities. The American Journal of Tropical Medicine and Hygiene, 72, 209-220.

Hauzy, C., Gauduchon, M., Hulot, F. D., \& Loreau, M. (2010). Density-dependent dispersal and 
relative dispersal affect the stability of predator-prey metacommunities. Journal of Theoretical Biology, 266, 458-69.

Holyoak, M., \& Lawler, P. (1996). The role of dispersal in predator-prey metapopulation dynamics. Journal of Animal Ecology, 65, 640-652.

Ignatieva, M., Stewart, G. H., \& Meurk, C. (2011). Planning and design of ecological networks in urban areas. Landscape and Ecological Engineering, 7, 17-25.

Jackman, S., Tahk, A., Zeileis, A., Maimone, C., \& Fearon, J. (2013). Package “pscl .” Stanford, CA.

Juliano, S. A., \& Reminger, L. (1992). The relationship between vulnerability to predation and behavior of larval treehole mosquitoes: geographic and ontogenetic differences. Oikos, 63, 465476.

Kittayapong, P., \& Strickman, D. (1993). Distribution of container-inhabiting Aedes larvae (Diptera: Culicidae) at a dengue focus in Thailand. Journal of Medical Entomology, 30, 601-606.

Lei, G.-C., \& Hanski, I. (1997). Metapopulation structure of Cotesia melitaearum, a specialist parasitoid of the butterfly Melitaea cinxia. Oikos, 78, 91-100.

Levins, R. (1969) Some demographic and genetic consequences of environmental heterogeneity for biological control. Bulletin of the Entomological Society of America, 15, 237-240.

Lounibos, L. P. (1983). The mosquito community of treeholes in subtropical Florida. Phytotelmata: terrestrial plants as hosts for aquatic insect communities, 223-246.

Lundkvist, E., Landin, J., \& Karlsson, F. (2002). Dispersing diving beetles ( Dytiscidae ) in agricultural and urban landscapes in. 39, 109-123.

MacArthur, R. H., \& Wilson, E. O. (1967). The Theory of Island Biogeography. Princeton: Princeton 


\section{University Press.}

Mazerolle, M. J., Villard, M., De, D., \& Moncton, U. De. (1999). Patch characteristics and landscape context as predictors of species presence and abundance: A review 1. 6, 117-124.

McGarigal, K., \& Marks, B. J. (1994). Fragstats: Spatial Pattern Analysis Program for Quantifying Landscape Structure. Corvallis, OR.

Meher-Homji, V. M. (1991). Probable impact of deforestation on hydrological processes. Climatic Change, 19, 163-173.

Morin, P. J. (2011). Community Ecology. Oxford: Wiley-Blackwell.

Nachman, G. (1987). Systems Analysis of Acarine Predator-Prey Interactions. II. The Role of Spatial Processes in System Stability. Journal of Animal Ecology, 56, 267-281.

Namba, T., Umemoto, a, \& Minami, E. (1999). The effects of habitat fragmentation on persistence of source-sink metapopulations in systems with predators and prey or apparent competitors. Theoretical Population Biology, 56, 123-37.

Orrock, J. L., Danielson, B. J., Burns, M. J., \& Levey, D. J. (2003). Spatial ecology of predator-prey interactions: corridors and patch shape influence seed predation. Ecology, 84, 2589-2599.

Overgaard, H. J., Ekbom, B., Suwonkerd, W., \& Takagi, M. (2003). Effect of landscape structure on anopheline mosquito density and diversity in northern Thailand : Implications for malaria transmission and control. Landscape Ecology, 18, 605-619.

Paradise, C. J., Blue, J. D., Burkhart, J. Q., Goldberg, J., Harshaw, L., et al. (2008). Local and regional factors influence the structure of treehole metacommunities. BMC Ecology, 16, 1-16. 
Patz, J. a, Olson, S. H., Uejio, C. K., \& Gibbs, H. K. (2008). Disease emergence from global climate and land use change. The Medical Clinics of North America, 92, 1473-1491, xii.

Ryall, K. L., \& Fahrig, L. (2006). Concepts \& synthesis response of predators to loss and fragmentation of prey habitat: a review of theory. Ecology, 87, 1086-1093.

Samways, M. J., \& Steytler, N. S. (1996). Dragonfly (Odonata) distribution patterns in urban and forest landscapes, and recommendation for riparian management. Biological Conservation, 3207, 279_288.

Shulman, R. S., \& Chase, J. M. (2007). Increasing isolation reduces predator:prey species richness ratios in aquatic food webs. Oikos, 116, 1581-1587.

Sih, A. (1986). Antipredator Responses and the Perception of Danger by Mosquito Larvae. Ecology, 67, 434-441.

Silberbush, A., \& Blaustein, L. (2011). Mosquito females quantify risk of predation to their progeny when selecting an oviposition site. Functional Ecology, 25, 1091-1095.

Steffan, W. A. (1975). Systematics and biological control potential of Toxorhynchites (Diptera: Culicidae). Mosquito systematics, 7, 59-68.

Vanwambeke, S. O., Lambin, E. F., Eichhorn, M. P., Harbach, R. E., Oskam, L., et al. (2007). Impact of Land-use Change on Dengue and Malaria in Northern Thailand. EcoHealth, 4, 37-51.

Walde, S. J. \& Nachman, G. (1999) Dynamics of spatially structured spider mite populations. Theoretical Approaches to Biological Control (eds B.A. Hawkins \& H.V. Cornell), pp. 163-189. Cambridge University Press, Cambridge, UK.

Yasuoka, J., \& Levins, R. (2007). Impact of deforestation and agricultural development on anopheline 
ecology and malaria epidemiology. The American Journal of Tropical Medicine and Hygiene, 76, $450-460$.

Zeileis, A., Kleiber, C., \& Jackman, S. (2008). Regression Models for Count Data in R.

Zuur, A. F., Ieno, E. N., Walker, N., Saveliev, A. a., \& Smith, G. M. (2009). Mixed effects models and 
Table 1. Predator species and their occurrence in water-filled containers. The first section displays the predators in the experimental 5-L containers. The second part displays the predators in per-established containers with a varying size $(2$ to $50 \mathrm{~L}$ ). Number of containers are the total number in which we found a specific predator. Total weeks are the number of weeks a predator was present in a container summed for all containers. Maximum per container is the maximum number of individuals of a predator taxon recorded in a single container.

\begin{tabular}{|c|c|c|c|}
\hline Predator species/family & $\begin{array}{l}\text { Number of } \\
\text { containers }\end{array}$ & Total weeks & $\begin{array}{l}\text { Maximum per } \\
\text { container }\end{array}$ \\
\hline Toxorhynchitis splendens (Diptera: Culicidae) & 14 & 47 & 9 \\
\hline Kaloula pulchra (Anura: Neobatrachia) & 3 & 3 & 1 \\
\hline Naucoridae (Hemiptera) & 1 & 5 & 4 \\
\hline Gerridae (Hemiptera) & 1 & 1 & 1 \\
\hline Vellidae (Hemiptera) & 10 & & 21 \\
\hline Notonectidae (Hemiptera) & 7 & & 48 \\
\hline Pleidae (Hemiptera) & 3 & & more than 150 \\
\hline Kaloula pulchra & 3 & & 2 \\
\hline Hydrophilidae (Coleoptera) & 3 & & 1 \\
\hline Toxorhynchitis splendens & 1 & & 3 \\
\hline Diplonychus sp. (Hemiptera) & 1 & & 1 \\
\hline Odonata & 1 & & 1 \\
\hline
\end{tabular}


Table 2. Comparison of all hurdle models using the explanatory variables habitat $(\mathrm{H})$, distance to forest (DF), connectance of surface water (WC) and connectance of forest habitat (FC), where $\mathrm{k}=$ number of parameters, AICc $=$ Akaike's corrected information criteria, $\Delta_{\mathrm{i}}=$ difference in AICc in comparison to the best model, and $\mathrm{w}_{\mathrm{i}}=$ model weight.

\begin{tabular}{lllll}
\hline Model parameters & $\mathbf{k}$ & AICc & $\boldsymbol{\Delta}_{\mathbf{i}}$ & $\mathbf{w}_{\mathbf{i}}$ \\
\hline H+DF+WC & 8 & 523.74 & 0.00 & 0.49 \\
H+WC & 6 & 523.78 & 0.04 & 0.49 \\
H+DF & 6 & 530.81 & 7.07 & 0.01 \\
H & 4 & 533.63 & 9.89 & 0.00 \\
H+DF+WC+FC & 10 & 535.12 & 11.38 & 0.00 \\
H+WC+FC & 8 & 539.00 & 15.26 & 0.00 \\
H+FC & 6 & 539.84 & 16.10 & 0.00 \\
DF+WC & 6 & 554.71 & 3.97 & 0.00 \\
DF+WC+FC & 8 & 555.31 & 31.57 & 0.00 \\
DF+FC & 6 & 557.55 & 33.81 & 0.00 \\
DF & 4 & 557.59 & 33.85 & 0.00 \\
WC+FC & 6 & 589.33 & 65.59 & 0.00 \\
WC & 4 & 589.90 & 66.17 & 0.00 \\
FC & 4 & 591.96 & 68.22 & 0.00 \\
Null model & 2 & 592.97 & 69.23 & 0.00 \\
\hline
\end{tabular}


Table 3. Parameter estimates and standard errors of the effects of habitat variables on the count (count model) and presence-absence (zero inflation model) components of the hurdle models for the first week of colonization in the averaged model and the best model.

\begin{tabular}{lcc}
\hline Model parameter & $\begin{array}{c}\text { Best model } \\
\text { Estimate }( \pm \text { SE) }\end{array}$ & $\begin{array}{c}\text { Averaged model } \\
\text { Estimate }( \pm \text { SE) }\end{array}$ \\
\hline Count model & & \\
Habitat factor & $0.15(0.03)$ & $0.14(0.03)$ \\
Distance to forest & $0.09(0.09)$ & $0.09(0.10)$ \\
Forest connectivity & - & $-0.03(0.05)$ \\
Water connectivity & $0.29(0.07)$ & $0.29(0.07)$ \\
\hline Zero inflation model & & \\
Habitat factor & $0.83(0.24)$ & $0.96(0.27)$ \\
Distance to forest & $-0.73(0.26)$ & $-0.73(0.26)$ \\
Forest connectivity & - & $0.16(0.35)$ \\
Water connectivity & $-0.23(0.23)$ & $-0.24(0.23)$ \\
\hline
\end{tabular}


Table 4. Spearman correlation coefficients of the modelled variables versus the habitat types.

\begin{tabular}{lllllllll}
\hline & Urban & $\boldsymbol{P}$-value & Water & $\boldsymbol{P}$-value & Forest & $\boldsymbol{P}$-value & Agriculture & $\boldsymbol{P}$-value \\
\hline First week & -0.19 & 0.394 & 0.00 & 0.991 & 0.62 & 0.002 & -0.51 & 0.014 \\
Colonized & -0.13 & 0.554 & -0.09 & 0.667 & 0.74 & $<0.001$ & -0.66 & 0.001 \\
Species & 0.06 & 0.790 & -0.02 & 0.945 & 0.49 & 0.017 & -0.43 & 0.042 \\
\hline
\end{tabular}


Table 5. Parameter estimate for three cumulative linear mixed effect models investigating the effect of predator presence on mosquito larvae abundance. The first model considered all mosquito larvae, whereas the second model used Aedes spp. larvae only and the third model used Culex spp. Larvae only. The estimates display the effect of predator presence on the prey abundance.

\begin{tabular}{lccc}
\hline Model & Estimate $(\mathbf{S E})$ & Z-value & $\boldsymbol{P}$-value \\
\hline Mosquito larvae & $-2.66(0.51)$ & -5.19 & $<0.001$ \\
Aedes spp. larvae & $-3.43(0.49)$ & -7.01 & $<0.001$ \\
Culex spp. larvae & $-1.22(0.45)$ & -2.74 & 0.006 \\
\hline
\end{tabular}


Table 6. Parameter estimates for the generalized linear mixed effects model for assessing differences in prey intake by Toxorhynchites splendens, in which each experimental unit was used as a random effect. Aedes spp. larvae were consumed in higher rates than Culex spp. larvae

\begin{tabular}{llll}
\hline Parameter & Estimate (SE) & $\boldsymbol{Z}$-value & $\boldsymbol{P}$-value \\
\hline Intercept (Aedes spp.) & $0.63(0.60)$ & 1.05 & 0.292 \\
Culex spp. & $-0.64(0.17)$ & -3.82 & $<0.001$ \\
Log(prey density) & $0.54(0.18)$ & 2.95 & 0.003 \\
\hline
\end{tabular}


1 Fig. 1. Study area and sampling sites. White dots represent the sampling sites, black areas represent

2 urban areas, dark grey areas represent forest areas, light grey areas represent water and black and grey

3 lines represent main roads.

4

5 Fig. 2. Visual representation of the effect of predator presence on the amount of Aedes spp. larvae. The 6 categories at the x-axis represent the number of Aedes spp. larvae. The dark grey part of the bars

7 represent the percentage of case in which predators were absent and the light grey part the percentage

8 of cases in which predators were present. Each week in which a container was checked was considered 9 as a single (dependent) sample. 
Figure 1

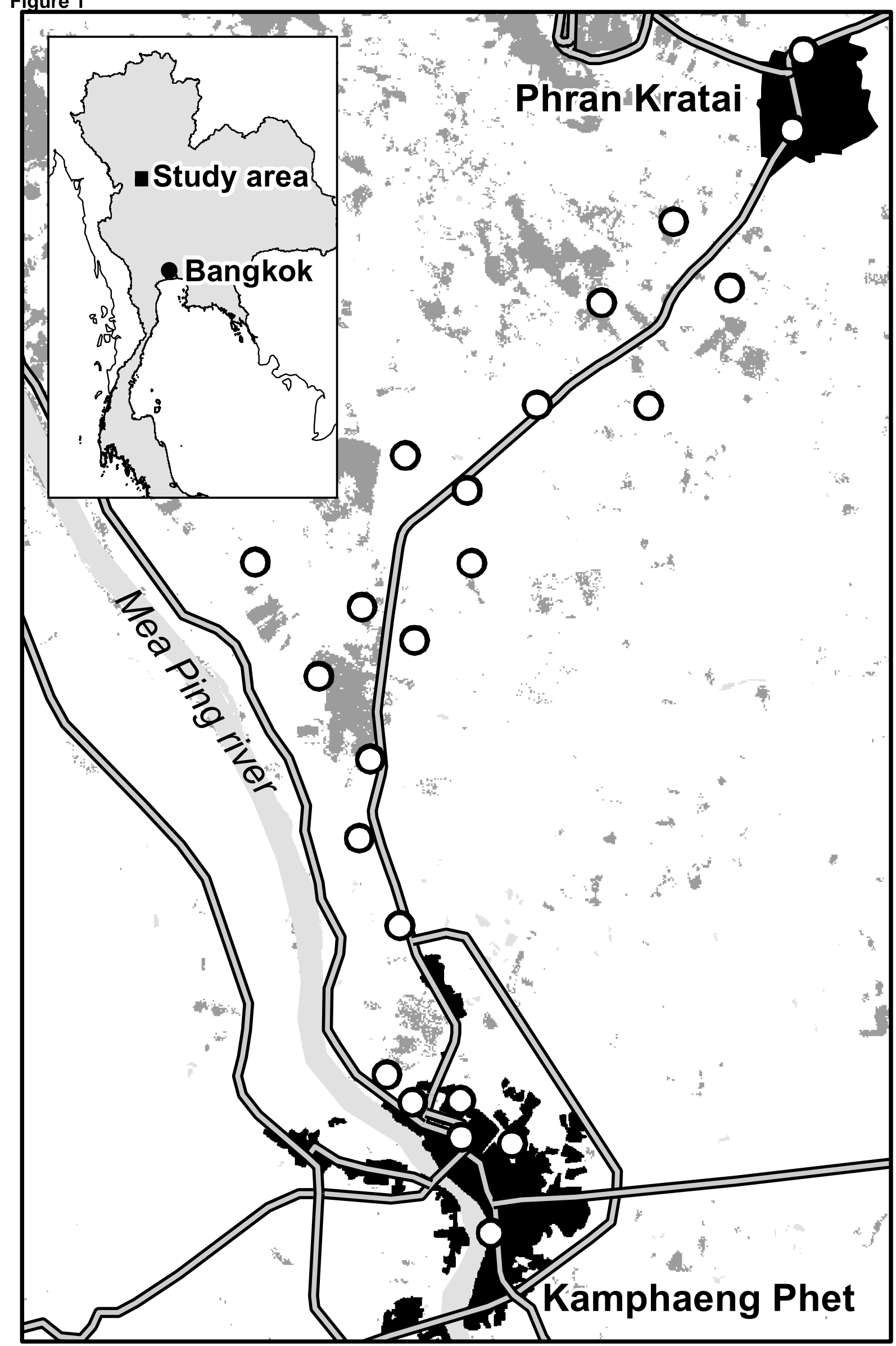

$\begin{array}{ccccc}0 & 2.5 & 5 & 10 \text { Kilometers } \\ & 1 & 1 & 1 & \end{array}$




$$
\mathrm{n}=64 \quad \mathrm{n}=1 \quad \mathrm{n}=24 \quad \mathrm{n}=28 \quad \mathrm{n}=22 \quad \mathrm{n}=5
$$

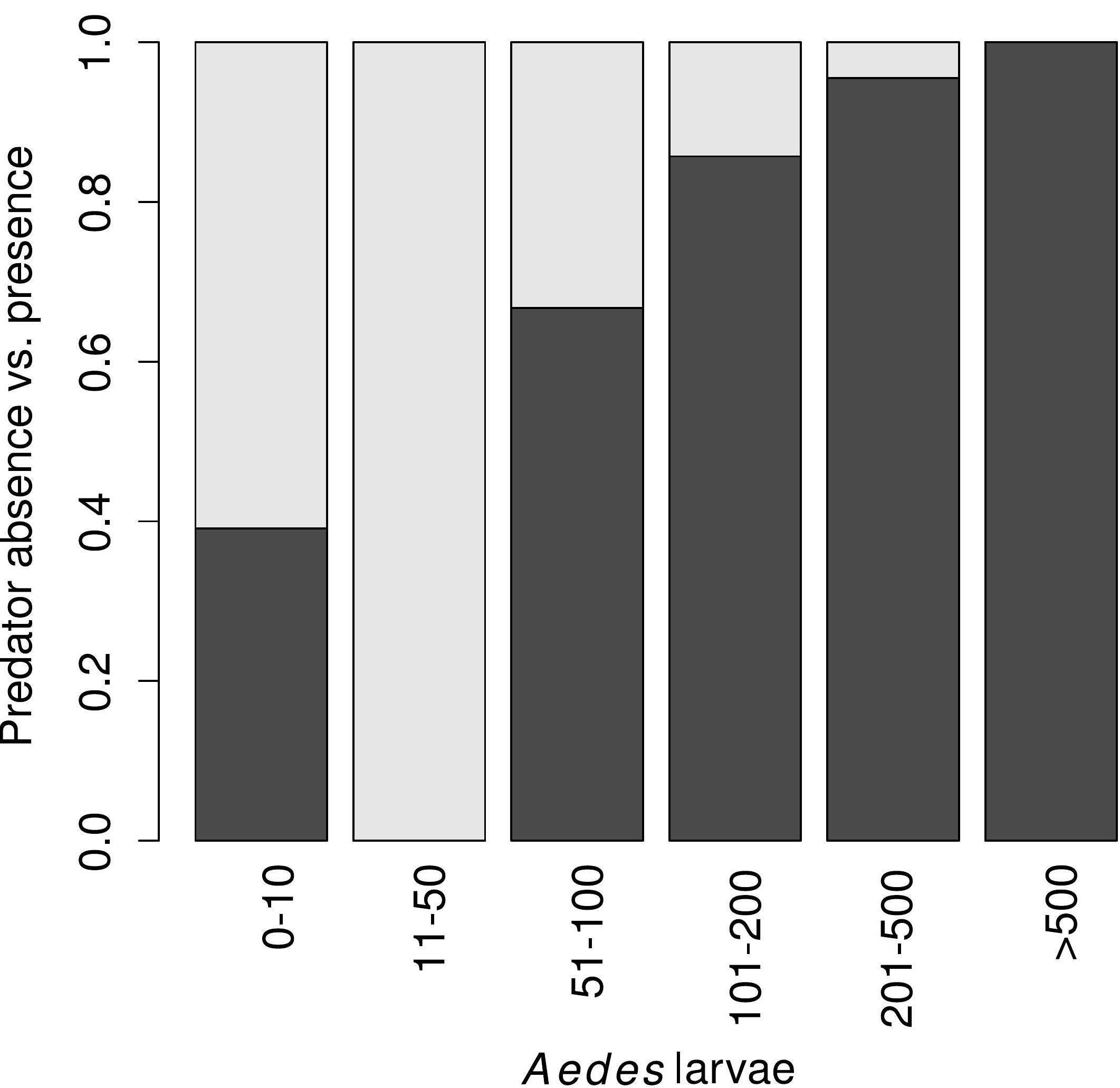

